\title{
Relationships between residual feed intake, average daily gain, and feeding behavior in growing dairy heifers
}

\author{
T. C. Green, J. G. Jago, K. A. Macdonald, and G. C. Waghorn ${ }^{1}$ \\ DairyNZ Ltd., Private Bag 3221, Hamilton 3240, New Zealand
}

\begin{abstract}
Residual feed intake (RFI) is a measure of an individual's efficiency in utilizing feed for maintenance and production during growth or lactation, and is defined as the difference between the actual and predicted feed intake of that individual. The objective of this study was to relate RFI to feeding behavior and to identify behavioral differences between animals with divergent RFI. The intakes and body weight (BW) of 1,049 growing dairy heifers (aged 5-9 mo; $195 \pm 25.8 \mathrm{~kg}$ of BW) in 5 cohorts were measured for 42 to $49 \mathrm{~d}$ to ascertain individual RFI. Animals were housed in an outdoor feeding facility comprising 28 pens, each with 8 animals and 1 feeder per pen, and were fed a dried, cubed alfalfa diet. This forage diet was chosen because most dairy cows in New Zealand are grazed on ryegrassdominant pastures, without grain or concentrates. An electronic feed monitoring system measured the intake and feeding behavior of individuals. Feeding behavior was summarized as daily intake, daily feeding duration, meal frequency, feeding rate, meal size, meal duration, and temporal feeding patterns. The RFI was moderately to strongly correlated with intake in all cohorts $(\mathrm{r}$ $=0.54-0.74)$, indicating that efficient animals ate less than inefficient animals, but relationships with feeding behavior traits (meal frequency, feeding duration, and feeding rate) were weak $(\mathrm{r}=0.14-0.26)$, indicating that feeding behavior cannot reliably predict RFI in growing dairy heifers. Comparison of the extremes of RFI (10\% most and 10\% least efficient) demonstrated similar BW and average daily gain for both groups, but efficient animals ate less; had fewer, longer meals; shorter daily feeding duration; and ate more slowly than the leastefficient animals. These groups also differed in their feeding patterns over $24 \mathrm{~h}$, with the most efficient animals eating less and having fewer meals during daylight (0600 to $2100 \mathrm{~h}$ ), especially during the afternoon (1200 to $1800 \mathrm{~h}$ ), but ate for a longer time during the night (0000-0600 h) than the least-efficient animals. In sum-
\end{abstract}

Received August 26, 2012.

Accepted January 8, 2013.

${ }^{1}$ Corresponding author: garry.waghorn@dairynz.co.nz mary, correlations between RFI and feeding behavior were weak. Small differences in feeding behavior were observed between the most- and least-efficient animals but adverse behavioral effects associated with such selection in growing dairy heifers are unlikely.

Key words: residual feed intake, behavior, Holstein heifer, alfalfa cube

\section{INTRODUCTION}

Feed accounts for approximately $50 \%$ of the costs of milk production from pasture in New Zealand (Waghorn and Hegarty, 2011) and also in dairy systems in the United States (USDA-ERS, 2011); therefore, improving the efficiency of feed utilization provides an opportunity for reducing production costs. Animals that use feed efficiently will require less feed for maintenance and for the same level of production (e.g., growth or milk production), and will, therefore, be more profitable. Better utilization of feed may mean less wastage and lower methane emissions (Waghorn and Hegarty, 2011), which could have positive environmental implications.

This variation in the efficiency of feed utilization for maintenance or production is known as residual feed intake (RFI), defined here as the difference between the actual and predicted feed intake of an animal, based on its BW and ADG (Richardson and Herd, 2004). Residual feed intake is also sometimes called net feed intake or feed conversion efficiency. Measurement of feed intake and BW gain, usually over a period of several weeks, enables individuals that use their feed more or less efficiently to be identified.

The biological mechanisms controlling RFI are not fully understood, but include digestion, physiological demands for nutrients, and biochemical efficiencies of feed utilization (Herd and Arthur, 2009). This biological bases of RFI, and the high percentage of lifetime energy intake that is used for growth and maintenance in pasture-fed dairy cows (Waghorn et al., 2012) justified the use of growing animals to identify divergence for lactation, and evaluation before puberty lessened disturbances associated with estrus. Feeding behavior may also contribute to variations in efficiency through the 
energetic costs associated with feeding activity, such as time spent feeding, rate of eating, and nutrient supply (Richardson and Herd, 2004; Lancaster et al., 2009; Kelly et al., 2010), and effects on intake will influence both production and RFI.

Published studies from beef cattle with divergent RFI have reported differences in feeding behavior characteristics (Nkrumah et al., 2007; Lancaster et al., 2009). Characteristics that have been measured include meal frequency, daily feeding duration, feeding rate, meal size, and meal duration. However, studies with beef cattle have involved grain and silage diets and have given highly variable results, with each trait accounting for 3 to $24 \%$ of the variation in RFI (Nkrumah et al., 2007; Lancaster et al., 2009; Montanholi et al., 2010). No published studies exist that investigate relationships between RFI and feeding behavior of dairy cattle fed forage diets, so alfalfa cubes were fed in this study because intakes could be measured accurately, composition was consistent, and the cubes had a high fiber content.

An understanding of factors associated with RFI, such as feeding behavior, will provide a better understanding of the mechanisms regulating efficiency and could help predict RFI if relationships are sufficiently strong (Nkrumah et al., 2007; Montanholi et al., 2010). An improved understanding of feeding behavior could improve animal management and production, and it is important to ensure that genetic selection for RFI will not result in associated adverse effects. This determination of RFI (Waghorn et al., 2012) and behavior was undertaken in animals that will be intensively grazed on temperate ryegrass dominant pastures during lactation. Pasture management usually involves an allocation of fresh pasture twice daily and cows graze competitively because the postgrazing residual DM must be low, to maintain sward quality (Holmes and Roche, 2007).

This study measured the behavior of young (5-9 mo) dairy heifers during selection to identify individuals with negative RFI (efficient) and positive RFI (inefficient). The hypothesis tested that RFI was related to feeding behavior and that behavioral differences exist between groups with divergent RFI. This evaluation was part of a trial to identify dairy cows with divergent RFI in New Zealand (Waghorn et al., 2012).

\section{MATERIALS AND METHODS}

\section{Animals and Facility}

This study used data collected from 1,049 female Holstein-Friesian calves at 5 to 9 mo of age. The trial is described in detail in Waghorn et al. (2012), so only a brief description is given here. Animals were at least fifteen-sixteenths Holstein-Friesian, of known parentage, free of disease, and $>30 \mathrm{~kg}$ at 4 to $10 \mathrm{~d}$ of age. The 1,049 calves were born (July/August) over $3 \mathrm{yr}$ and were screened for divergence in RFI in 5 cohorts in the summer/fall of each year in an outdoor feeding facility at the Westpac Taranaki Agricultural Research Station in Hawera, New Zealand [global positioning system (GPS) coordinates: $\left.-39^{\circ} 61^{\prime} \mathrm{S}, 174^{\circ} 30^{\prime} \mathrm{E}\right]$. Cohort 1 was assessed in 2008, cohorts $2 \mathrm{a}$ and $2 \mathrm{~b}$ in 2009 , and cohorts $3 \mathrm{a}$ and $3 \mathrm{~b}$ in 2010.

All animals were identified by electronic identification (EID) and in each cohort they were randomly allocated to 1 of 28 pens ( 8 animals in most pens) at the commencement of the trial. Each pen was $42 \mathrm{~m}^{2}(6 \times$ $7 \mathrm{~m}$ ), with a chute of about $1.8 \mathrm{~m}$ in length leading to a single feeding station, enabling only 1 animal access to the feed at a time. The feeding station comprised a feed bin mounted on load bars and an EID reader. The animals were held in pens for an 11-d acclimatization period followed by a measurement period of 42 to $49 \mathrm{~d}$. They were fed dried alfalfa (Medicago sativa) cubes (Kapt-Al Grain \& Storage Ltd., Vancouver, BC, Canada; $84.5 \% \mathrm{DM}$ ), and water and mineral salt blocks (Dominion Salt Ltd., Mount Maunganui, New Zealand) were freely available. The pens had deep bedding of wood shavings, with a concrete apron adjacent to the feeding station. Allocation of 8 animals per pen was based on preliminary evaluations that indicated sufficient time was available for 8 animals to eat ad libitum from a single feeding station.

Feed was available for about $23 \mathrm{~h} / \mathrm{d}$, with access denied between about 0800 and $0900 \mathrm{~h}$ for replenishment of cubes and cleaning. The decision to house 8 animals/pen was based on preliminary measurements (Waghorn et al., 2012), which showed that intakes were not affected by increasing animal numbers from 6 to 8 per feeding station.

\section{Data Recording and RFI}

Data used for these analyses comprised BW, animal EID, feed intakes, and the time and duration of individuals eating from the feed bin, and were recorded by an automatic recording system (Gallagher Group Ltd., Hamilton, New Zealand). Three-times-per-week measurements of BW (Gallagher SmartScale 500 data collector; Gallagher Group Ltd.) were used for calculation of ADG and RFI, as detailed by Waghorn et al. (2012). Animals were identified upon entry to the feed bin by an EID reader (Gallagher G03103 R series panel reader; Gallagher Group Ltd.) positioned over the feed bin. Feed bin weight was measured by load bars (Gallagher G01100 SmartScale 300/400 weigh scale; Gallagher Group Ltd.) located beneath each bin, allowing 
calculation of feed intake. In conjunction with EID of individuals accessing feed, measurements provided information on circadian patterns of intake, amount consumed, number and duration of meals, and these data enabled calculation of meal size, intake rate, meal frequency and daily feeding duration for individual animals. Data were processed and information from all 28 feed bins was logged onto 2 computers at 1-s intervals.

The feeding data obtained from the animals during their time in the facility were checked for errors, resulting in removal of 750 from more than 55,000 animalday records (Waghorn et al., 2012). The main cause of data removal was load bar and, occasionally, electrical failure and when this occurred, behavioral data for all animals in affected pens on that day were omitted. Other criteria for data removal included all negative meal weights, which were excluded from the intake calculations, but meal events with intakes of -0.5 to $0.0 \mathrm{~kg}$ were included in the analyses of behavioral traits because the animal had accessed the feed bin. Minor fluctuations or rounding in the weighing, especially if animals pushed down on the cubes, may have been responsible for small negative values, but larger negative values $(<-0.5 \mathrm{~kg})$ indicated a load bar problem and all data were excluded for the animal for that day. Another criterion for data exclusion was a feeding rate greater than $200 \mathrm{~g}$ of cubes/min during a meal in which more than $0.5 \mathrm{~kg}$ of cubes were consumed, because this was not possible, and the data from the animal on that day excluded. The hardness and high DM content of the cubes meant that they required significant chewing and salivation, which limited the rate of intake and made it physically impossible to consume a large quantity of dry cubes in a short period.

Average daily gain was calculated by regressing BW measurements over the trial period. Feed requirements were predicted for animals in each cohort by regressing actual intake $(\mathrm{kg} / \mathrm{d})$ against $\mathrm{ADG}(\mathrm{kg} / \mathrm{d})$ and mean metabolic BW $\left(\mathrm{kg}^{0.75}\right)$ as described by Waghorn et al. (2012). The RFI was estimated as the residuals after multiple regression of intake on $\mathrm{ADG}(\mathrm{kg} / \mathrm{d})$ of all animals and mean metabolic $\mathrm{BW}\left(\mathrm{kg}^{0.75}\right.$ of $\left.\mathrm{BW}\right)$ at the trial midpoint. The model fitted was as follows: $\mathrm{Y}_{\text {int }}=$ $\mathrm{C}+\mathrm{b}_{1} \mathrm{ADG}+\mathrm{b}_{2} \mathrm{BW}+\mathrm{RFI}$, where $\mathrm{Y}_{\text {int }}$ was the mean daily feed intake $(\mathrm{kg}$ of $\mathrm{DM} / \mathrm{d}), \mathrm{C}$ was the intercept, $\mathrm{b}_{1}$ and $b_{2}$ were partial regression coefficients, ADG was in kilograms per day, BW was mean $\mathrm{BW}^{0.75}(\mathrm{~kg})$ at the trial midpoint, and RFI $(\mathrm{kg} / \mathrm{d})$ was the residual error (i.e., actual intake minus predicted feed requirements). Efficient animals have negative RFI values, as they eat less than predicted; inefficient animals have positive RFI values.

Feeding behavior was described in terms of average daily intake $(\mathrm{kg} / \mathrm{d})$, meal frequency (number/d), feed- ing duration $(\mathrm{h} / \mathrm{d})$, daily feeding rate $(\mathrm{g} / \mathrm{min})$, meal amount $(\mathrm{kg} / \mathrm{meal})$, and meal duration (min/meal). A meal was defined as being a feeding event in which $\geq 0.01 \mathrm{~kg}$ of cubes were consumed. The meal ended when the animal left the feed bin for more than $15 \mathrm{~min}$, or when another animal entered the feed bin. Unless otherwise stated, all feed weights are presented as wet weight of cubes ( $84.5 \% \mathrm{DM})$.

\section{Behavioral and Temporal Analyses}

Analyses of performance and feeding behavior were undertaken for all animals in the trial $(\mathrm{n}=1,049)$. In addition to that, the $10 \%$ most- and $10 \%$ least-efficient animals from each cohort were evaluated for both daily feeding behavior and temporal feeding patterns $(\mathrm{n}=$ 208; 104 in each efficiency group). Animal numbers were the same for efficient and inefficient individuals within a cohort.

Analyses of temporal feeding patterns were based on the times of day that divergent animals consumed their feed. The 24-h day was divided into eight 3 -h time periods (0000-0300, 0300-0600 h, and so on) and average intake, meal frequency, and feeding duration were summarized for each of these periods.

\section{Statistical Analyses}

Most analyses were undertaken with individual cohorts because they differed in year of trial, season of testing, animal age, and BW. Pooled analyses were undertaken with data combined from all cohorts, with cohort included in the model. However, animals were of a similar breed and genetic merit (Waghorn et al., 2012), and were fed and managed in a similar manner over the $3 \mathrm{yr}$ of measurements. Mean values for intake and feeding behavior parameters in tables are means of data. However, variations between individuals in their behavior resulted in a large variation in values for some parameters, especially meal frequency, meal size, and meal duration, and the large standard error of means will result in incorrect estimates if these are used to calculate other parameters. For example, using means of meal frequency $\times$ meal duration overestimates feeding duration; values for feeding duration (and intake) were calculated for each animal and then analyzed.

Cohort Correlations. Correlations between both ADG and RFI with feeding behavior characteristics (intake, meal frequency, feeding duration, feeding rate, meal size, and meal duration) were calculated by regression analysis for each cohort using GenStat software (Payne et al., 2009). Pooled within-cohort correlations between RFI and the feeding behavior characteristics were also calculated. 
Table 1. Number of animals, days in the facility, and trial length (d) of animals at the start of measurements (d) for each cohort (mean \pm SD)

\begin{tabular}{lrrrrr}
\hline & \multicolumn{5}{c}{ Cohort } \\
\cline { 2 - 6 } Item & \multicolumn{1}{c}{1} & $2 \mathrm{a}$ & $2 \mathrm{~b}$ & $3 \mathrm{a}$ & $3 \mathrm{~b}$ \\
\hline Number of animals & 164 & 219 & 219 & 224 & 223 \\
Days in the facility & 91 & 60 & 60 & 60 & 60 \\
Trial length (d) & 42 & 47 & 49 & 48 & 48 \\
\hline
\end{tabular}

Comparison of 10\% Most- and 10\% LeastEfficient Animals. The performance and feeding behavior of the $10 \%$ most- and $10 \%$ least-efficient individuals from each cohort were compared using ANOVA in GenStat. The cohorts were combined in a pooled within-cohort analysis (i.e., cohort included in the model), which allowed an overall comparison of the divergent groups (RFI extremes) from all cohorts. This analysis provided a numerical summary of divergence and average values for RFI, relative to ADG, BW, intake and feeding behavior for the most (low-RFI) and least (high-RFI) efficient groups.

Temporal Feeding Patterns. Analyses of temporal feeding patterns were undertaken with a repeated measures analysis using the AREPMEASURES procedure in GenStat, with time included as a factor, to determine if differences existed in feeding behavior between the most and least efficient animals during a 24-h day. All 3 variables (average intake, meal frequency, and feeding duration) had significant interactions between time and efficiency group $(P<0.001)$, so this interaction was explored at each 3 -h time interval over the trial period (42-49 d). The mean intake, meal frequency, and feeding duration of the $10 \%$ most- and least-efficient animals in each cohort were compared in each 3 -h time interval (commencing at $0000 \mathrm{~h}$ ) using ANOVA in a pooled within-cohort analysis to determine feeding patterns over a 24 -h day. In addition to comparison between efficiency groups, the feeding patterns were also compared within each efficiency group (i.e., the change in feeding activity of the most efficient or least efficient over $24 \mathrm{~h}$ ).

\section{RESULTS}

The animals accepted the cube diet and adapted readily to the feeding facility during the pretrial period. Dry matter intake averaged $6.7 \mathrm{~kg} / \mathrm{d}(8.0 \mathrm{~kg}$ of cubes/d) and ADG (all animals) averaged $0.88 \mathrm{~kg} / \mathrm{d}$. The alfalfa cubes contained $45.8 \% \mathrm{NDF}$, with a predicted ME of $9.1 \mathrm{MJ} / \mathrm{kg}$ of DM and an OM digestibility of $65 \%$ (Waghorn et al., 2012). Animal numbers and time in the facility are summarized in Table 1, and although birth dates of animals in cohorts $2 \mathrm{~b}$ and $3 \mathrm{~b}$ were $3 \mathrm{wk}$ later than cohorts $2 \mathrm{a}$ and $3 \mathrm{a}$, they were about $7 \mathrm{wk}$ older at the start of measurements.

The RFI, BW, and feeding behavior of each cohort are summarized in Table 2. Mean intakes of individuals ranged from 4.9 to $11.8 \mathrm{~kg} / \mathrm{d}$ across all cohorts. Animals in cohort 1 had an average intake of $9.4 \mathrm{~kg} / \mathrm{d}$, whereas the other cohorts averaged 6.9 to $8.3 \mathrm{~kg} / \mathrm{d}$ (Table 2). Within each cohort, some individuals initiated a large number of meals. For example, cohort 1 had a high average meal frequency per day (12), with several animals having $30+$ meals/d, but average meals per day for animals in other cohorts was 4.7 to 6.8. The average feeding duration per day ranged from 2.6 to $2.9 \mathrm{~h}$ /animal across cohorts, but from as little as 1.6 to more than $4.5 \mathrm{~h}$ for some individuals, indicating a large range in individual behavior. Feeding rate averaged $49.4 \mathrm{~g} / \mathrm{min}$ across all cohorts (Table 2), ranging from below 30 to more than $70 \mathrm{~g} / \mathrm{min}$ for individuals. The DM content of the cubes was $84.5 \%$, so mean DMI rate was $41.7 \mathrm{~g} / \mathrm{min}$. Meal size $(\mathrm{kg} / \mathrm{meal})$ ranged from 0.2 to $3.1 \mathrm{~kg} / \mathrm{meal}$, and meal duration from 4 to $87 \mathrm{~min}$.

\section{Correlations of Feeding Behavior with ADG and RFI}

Daily intake was positively correlated with ADG in all cohorts (Table 3), with faster-growing animals having greater intakes than slower-growing animals. Correlations between ADG and feeding behavior characteristics varied between cohorts, but meal frequency, daily feeding duration, and feeding rate tended to be positively correlated with ADG. Meal size and duration were not usually related to ADG (Table 3 ).

As expected, RFI and daily intake were strongly correlated (Table 4), indicating that the most-efficient animals ate less feed than the least-efficient animals. In general, correlations between RFI and other behavioral variables were weak and, although often statistically significant (Table 4), some inconsistencies were observed between cohorts. The main outcomes were significant correlations between feeding rate and meal frequency, with RFI (Table 4) indicating that the mostefficient animals ate more slowly and usually had fewer meals per day than the least-efficient animals. 


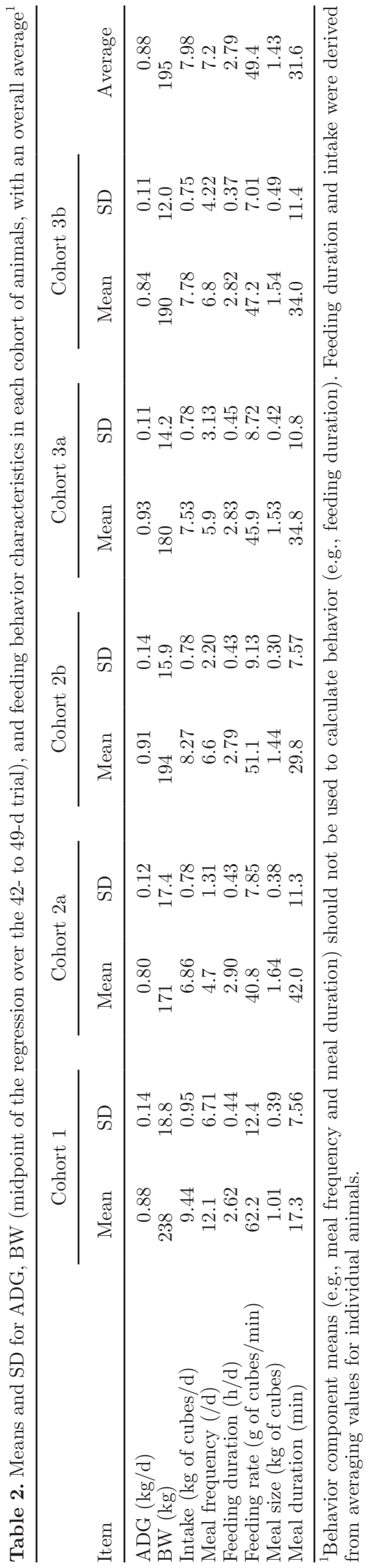

\section{Comparison of the $10 \%$ Most- and $10 \%$ Least-Efficient Animals}

A comparison of the $10 \%$ most-efficient and $10 \%$ least-efficient animals from all 5 cohorts demonstrated similar $(P>0.05) \mathrm{BW}$ and ADG despite the divergence in RFI $(P<0.001$; Table 5$)$. The most-efficient animals ate $1.78 \mathrm{~kg} / \mathrm{d}$ less than the least-efficient animals, and had fewer meals with less time spent eating per day (Table 5). They also had a slower feeding rate, and spent a longer time feeding at each meal $(P<0.05)$. No differences in meal size were observed $(P>0.05$; Table 5).

\section{Temporal Feeding Patterns of the 10\% Most- and 10\% Least-Efficient Animals}

The $10 \%$ most- and least-efficient animals from all cohorts differed in their temporal feeding patterns, with greatest differences between groups in the afternoon. From $0600 \mathrm{~h}$ to midnight, the most-efficient animals ate less $(P<0.05$; Figure 1a) and had fewer meals between 0600 and $2100 \mathrm{~h}(P<0.05$; Figure $1 \mathrm{~b})$ compared with the least-efficient animals. Between midnight and 0600 $\mathrm{h}$, the most-efficient animals spent more time eating than the least-efficient animals, but this pattern was reversed between 1200 and $1800 \mathrm{~h}$ (Figure 1c).

Comparison of the feeding activity within each efficiency group over $24 \mathrm{~h}$ revealed that, generally, the most-efficient group had a steady intake and meal frequency throughout $24 \mathrm{~h}$, whereas the least-efficient animals had greater intakes and meal frequencies during daylight (particularly during the afternoon) and lower during the night (Figures $1 \mathrm{a}$ and $1 \mathrm{~b}$ ). The mostefficient animals spent more time feeding at night than during daylight, but the least efficient spent more time feeding during the afternoon than at other times over $24 \mathrm{~h}$ (Figure 1c).

\section{DISCUSSION}

Behavioral differences between animals of divergent RFI may provide insight into mechanisms that underlie variations in RFI and, consequently, performance (Nkrumah et al., 2007). It is also desirable to investigate relationships between RFI and other traits, including behavior, to ensure that genetic selection for lower RFI (greater efficiency) will not have associated adverse effects in a commercial environment. Although the measurements reported here were undertaken with an alfalfa cube diet and 8 animals/feeder, the ADG (0.88 $\mathrm{kg} / \mathrm{d}$ ) was higher than about $0.77 \mathrm{~kg} / \mathrm{d}$ typical of heifers raised on pasture (Macdonald et al., 2005), suggesting that the animals were able to obtain sufficient feed 
Table 3. Correlation coefficients between intake and measures of feeding behavior with ADG (kg/d) for each cohort of animals

\begin{tabular}{lccccc}
\hline & \multicolumn{5}{c}{ Cohort } \\
\cline { 2 - 6 } Item & 1 & $2 \mathrm{a}$ & $2 \mathrm{~b}$ & $3 \mathrm{a}$ & $3 \mathrm{~b}$ \\
\hline Intake $(\mathrm{kg}$ of cubes/d) & $0.43^{* * *}$ & $0.67^{* * *}$ & $0.25^{* * *}$ & $0.60^{* * *}$ & $0.45^{* * *}$ \\
Meal frequency $(/ \mathrm{d})$ & -0.03 & $0.19^{* *}$ & $0.17^{*}$ & $0.13^{*}$ & 0.13 \\
Feeding duration (h/d) & -0.03 & 0.00 & $0.20^{* *}$ & $0.16^{*}$ & 0.09 \\
Feeding rate $(\mathrm{g}$ of cubes/min) & $0.23^{* *}$ & $0.40^{* * *}$ & -0.01 & $0.21^{* *}$ & $0.21^{* *}$ \\
Meal size (kg of cubes/meal) & $0.17^{*}$ & 0.11 & -0.11 & 0.03 & -0.05 \\
Meal duration (min/meal) & 0.02 & $-0.20^{* *}$ & -0.07 & -0.10 & -0.12 \\
\hline
\end{tabular}

${ }^{*} P<0.05 ;{ }^{*} P<0.01 ;{ }^{* * *} P<0.001$

despite the competition to access the feeding station. The feeders were occupied for most of the available time $(23 \mathrm{~h} / \mathrm{d})$ and animals may have had to compete for feed, but competitive ability is also a requirement under intensive pastoral grazing of temperate forages. Dairy farming in New Zealand is seasonal and based on ryegrass dominant pasture providing over $90 \%$ of the diet, and a new allocation of feed given after each milking. Cows must eat to a low residual DM to maintain sward quality (Holmes and Roche, 2007), so animals require a high rate of intake under this regimen, but cows are rarely fully fed. Although the environment used for determining behavioral characteristics and RFI in this study is quite different from pastoral grazing, the need for competitive feeding applies to both situations, and the analyses are relevant to both intensive grazing and the determination of RFI.

\section{Feeding Behavior and ADG}

Faster-growing animals ate more, tended to have more meals per day, spent more time feeding each day, and ate faster than slower-growing animals. The coefficients for the correlations between feeding behavior and ADG varied between cohorts, and relationships that were statistically significant were generally not as strong as those reported in other studies with beef cattle (Schwartzkopf-Genswein et al., 2002; Lancaster et al., 2009; Montanholi et al., 2010).

Correlations between meal frequency and ADG were lower than with intake, and their strength also varied between cohorts (Table 3 ). This indicates that this relationship is unlikely to be important, a view supported by the majority of similar investigations in beef cattle (Schwartzkopf-Genswein et al., 2002; Lancaster et al., 2009; Montanholi et al., 2010). Feeding rate was weakly to moderately correlated with ADG in 4 of the 5 cohorts in the present study (Table 3), and similar to findings in 2 beef animal studies $(\mathrm{r}=$ 0.26-0.32, $P<0.05$; Lancaster et al., 2009; Montanholi et al., 2010), although a third beef animal study reported no relationship (Kelly et al., 2010). Most studies with beef cows have reported weak-to-moderate associations between ADG and daily feeding duration, meal size, and meal duration (Schwartzkopf-Genswein et al., 2002; Lancaster et al., 2009; Montanholi et al., 2010), although such relationships were not evident in the work reported here. The variable results reported in the literature may be due to differences in facility designs, which had 1 to 8 animals/feeder and the beef cattle were usually older and with a higher ADG than the dairy heifers evaluated in this study, because most diets contained grain. Young animals were used in this study to avoid effects of estrus on behavior and their

Table 4. Correlation coefficients between intake and measures of feeding behavior with residual feed intake in each cohort of animals

\begin{tabular}{|c|c|c|c|c|c|}
\hline \multirow[b]{2}{*}{ Item } & \multicolumn{5}{|c|}{ Cohort } \\
\hline & 1 & $2 \mathrm{a}$ & $2 \mathrm{~b}$ & $3 \mathrm{a}$ & $3 \mathrm{~b}$ \\
\hline Intake (kg of cubes/d) & $0.63^{* * *}$ & $0.54^{* * *}$ & $0.61^{* * *}$ & $0.60^{* * *}$ & $0.74^{* * *}$ \\
\hline Meal frequency $(/ d)$ & $0.18^{*}$ & $0.23^{* * *}$ & $-0.14^{*}$ & $0.17^{*}$ & $0.21^{* *}$ \\
\hline Feeding duration $(\mathrm{h} / \mathrm{d})$ & 0.11 & $0.17^{*}$ & 0.06 & $0.14^{*}$ & $0.26^{* * *}$ \\
\hline Feeding rate ( $\mathrm{g}$ of cubes $/ \mathrm{min}$ ) & $0.20^{*}$ & $0.18^{* *}$ & $0.21^{* *}$ & $0.16^{*}$ & $0.24^{* * *}$ \\
\hline Meal size ( $\mathrm{kg}$ of cubes/meal) & 0.00 & -0.02 & $0.26^{* * *}$ & -0.04 & -0.04 \\
\hline Meal duration (min/meal) & -0.08 & -0.16 & 0.00 & $-0.20^{* *}$ & $-0.14^{*}$ \\
\hline
\end{tabular}

${ }^{*} P<0.05 ;{ }^{* *} P<0.01 ;{ }^{* * *} P<0.001$. 

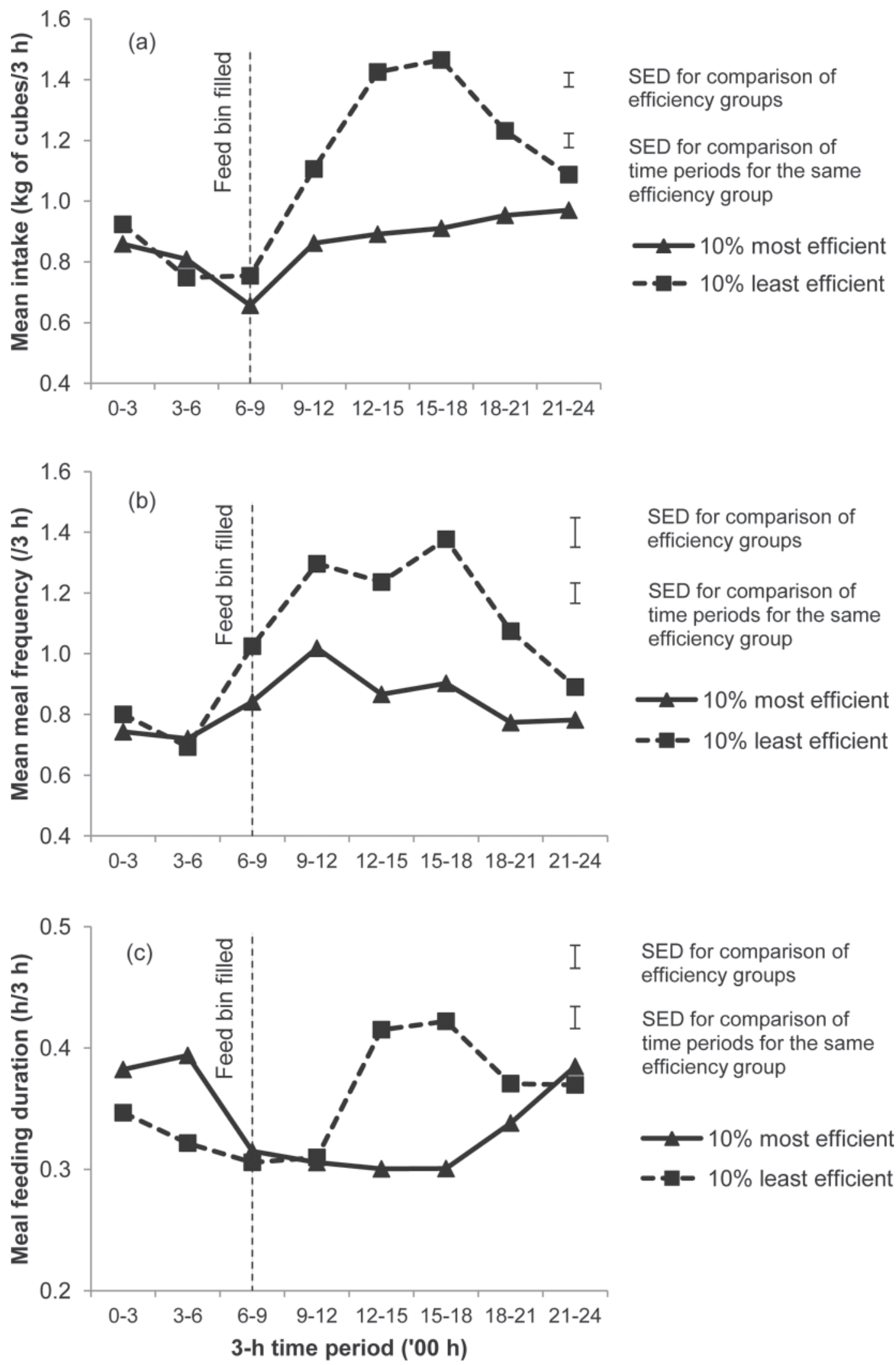

Figure 1. Mean (a) intake, (b) meal frequency, and (c) feeding duration per 3-h time period (commencing at midnight) of the $10 \%$ most- and least-efficient animals ( $\mathrm{n}=104$ per group) across all cohorts. Error bars indicate the standard error of the difference (SED). 
Table 5. Mean values of the $10 \%$ most $(\mathrm{n}=104)$ and $10 \%$ least $(\mathrm{n}=104)$ efficient animals across all cohorts for residual feed intake (RFI), ADG, BW (midpoint of the regression over the trial period), and measures of feeding behavior ${ }^{1}$

\begin{tabular}{lcccc}
\hline Item & $\begin{array}{c}10 \% \text { most } \\
\text { efficient }\end{array}$ & $\begin{array}{c}10 \% \text { least } \\
\text { efficient }\end{array}$ & SED $^{2}$ & $P$-value \\
\hline RFI $(\mathrm{kg}$ of cubes/d) & -0.96 & 0.82 & 0.05 & $<0.001$ \\
$\mathrm{ADG}(\mathrm{kg} / \mathrm{d})$ & 0.88 & 0.87 & 0.02 & 0.99 \\
$\mathrm{BW}(\mathrm{kg})$ & 195 & 196 & 2.20 & 0.53 \\
Intake $(\mathrm{kg}$ of cubes/d) & 6.97 & 8.75 & 0.10 & $<0.001$ \\
Meal frequency $/ \mathrm{d})$ & 6.3 & 8.2 & 0.61 & 0.002 \\
Feeding duration (h/d) & 2.71 & 2.85 & 0.07 & 0.026 \\
Feeding rate $(\mathrm{g}$ of cubes/min) & 45.4 & 53.0 & 1.36 & $<0.001$ \\
Meal size $(\mathrm{kg}$ of cubes/meal) & 1.44 & 1.48 & 0.06 & 0.47 \\
Meal duration (min/meal) & 35.6 & 30.6 & 1.54 & 0.001 \\
\hline${ }^{1}$ Behavior component means (e.g., meal frequency and meal duration) should not be used to calculate behavior \\
(e.g., feeding duration). Feeding duration and intake were derived from averaging values for individual animals. \\
${ }^{2}$ Standard error of the difference.
\end{tabular}

relative immaturity (BW was about $40 \%$ of mature BW) would limit energy partitioning to fat, which was important for estimating RFI. However all studies, with steer, bulls, or heifers, suggest that feeding behavior is not a good predictor of ADG.

\section{Feeding Behavior and RFI}

The correlations between RFI and feeding behavior variables in this study were weak despite many being statistically significant. No published studies on feeding behavior and RFI have been found for dairy cattle, but substantial literature is available for growing beef cattle. As expected, intake had the strongest relationship with RFI in this and other studies with growing beef cattle (Table 6), because efficient animals have smaller intakes than less-efficient animals for the same level of growth. Other behavioral traits measured here had weaker associations with RFI (Table 4), which corresponds with studies on beef cattle for meal frequency, feeding duration, feeding rate, and meal size (Table 6). This indicates that these feeding behaviors have little relationship to RFI in these dairy heifers. The large number of animals used in this study may have contributed to statistical significance despite low correlation coefficients, but all studies demonstrated similar relationships between behavior and RFI (Table 6).

Although the trends found in this and studies with growing beef animals (Table 6) follow similar patterns, differences in the relationships between behavioral traits and RFI may be a consequence of the systems used to measure the associations, including feeds, pen configuration, the animals, and also the analyses of observations. For example, differences in the numbers and type of animals used, the facility or housing setup, group size, and the diet fed can all have an effect on feeding behavior (Grant and Albright, 2001; Phillips, 2004; Huzzey et al., 2006).

\section{Comparison of the RFI Extremes}

Comparisons of the $10 \%$ most- and $10 \%$ least-efficient animals from all cohorts (RFI extremes) demonstrated similar BW and ADG, supporting the independence of RFI from production (Herd and Arthur, 2009). Animals in the most-efficient group ate about $20 \%$ less than the least-efficient group, and similar responses have been reported with beef animals (Golden et al., 2008; Bingham et al., 2009; Durunna et al., 2011). The shorter daily feeding times of efficient animals (Table 5) have

Table 6. Correlation coefficients for residual feed intake (RFI) and feeding behavior characteristics summarized from this study and from published reports for beef cattle fed concentrate- and silage-based diets

\begin{tabular}{|c|c|c|c|c|c|c|}
\hline Item & $\begin{array}{l}\text { This } \\
\text { study }^{1}\end{array}$ & $\begin{array}{l}\text { Robinson and } \\
\text { Oddy (2004) }\end{array}$ & $\begin{array}{l}\text { Nkrumah } \\
\text { et al. (2007) }\end{array}$ & $\begin{array}{l}\text { Lancaster } \\
\text { et al. (2009) }\end{array}$ & $\begin{array}{c}\text { Kelly } \\
\text { et al. (2010) }\end{array}$ & $\begin{array}{l}\text { Montanholi } \\
\text { et al. (2010) }\end{array}$ \\
\hline Intake $(\mathrm{kg}$ of $\mathrm{DM} / \mathrm{d})$ & $0.62^{*}$ & $0.57^{*}$ & & $0.60^{*}$ & $0.47^{*}$ & \\
\hline Meal frequency (no./d) & $0.14^{*}$ & $0.18^{*}$ & $0.18^{*}$ & $0.26^{*}$ & $0.45^{*}$ & 0.15 \\
\hline Feeding rate ( $\mathrm{g}$ of $\mathrm{DM} / \mathrm{min})$ & $0.20^{*}$ & $0.14^{*}$ & & & $0.26^{*}$ & $0.44^{*}$ \\
\hline Meal size ( $g$ of $\mathrm{DM})$ & 0.02 & & & & & $0.41^{*}$ \\
\hline Meal duration (min) & $-0.12^{*}$ & & & & & -0.15 \\
\hline
\end{tabular}

${ }^{1}$ Pooled within cohort correlations.

$* P<0.05$. 
also been reported in some beef studies with divergent groups (Nkrumah et al., 2006; Durunna et al., 2011), whereas others reported no differences (Dobos and Herd, 2008; Kelly et al., 2010; Montanholi et al., 2010).

However, the most-efficient animals ate about $15 \%$ more slowly than the least-efficient group, and similar findings were reported in some studies of growing beef cattle (Bingham et al., 2009; Kelly et al., 2010; Montanholi et al., 2010), but not in others (Dobos and Herd, 2008; Golden et al., 2008; Durunna et al., 2011). In this and other studies, the most-efficient animals had fewer meals per day than less-efficient animals (Bingham et al., 2009; Kelly et al., 2010; Durunna et al., 2011). Only one other study has reported meal size and duration, and their results differed from findings here (Montanholi et al., 2010).

The differences between studies may be due to experimental design, the parameters of behavior investigated, or the methods used to record outcomes. For example, in the current study, a meal was determined to have ended when it was 15 min or more before that individual next entered the feed bin. Other studies have used intervals of 5,7 , or $21 \mathrm{~min}$. These differing definitions could affect the number, size, and duration of meals recorded and, thus, the outcome of the studies. It was not clear from this and other studies whether differences in feeding behavior led to the differences in RFI, or differences in RFI affected behavioral traits.

\section{Temporal Feeding Patterns of the RFI Extremes}

As in the current study, measurements of growing beef cattle also demonstrated differences in temporal feeding patterns associated with RFI, but the mostefficient beef animals consumed less feed at night compared with the least-efficient animals (Montanholi et al., 2010; Lawrence et al., 2011). They found no differences between divergent groups in daytime intakes, whereas the current study showed a consistent intake over $24 \mathrm{~h}$ for efficient animals, but the least-efficient animals ate more during the afternoon/evening (Figure 1a). Golden et al. (2008) did not report differences in intake patterns of divergent animals, but they only had 6 to 9 steers/group.

Meal frequency of the most-efficient animals was lower during daylight/early evening (0600-2100 h) and this is consistent with a study on beef steers in which the most-efficient animals made fewer visits to the feeder $(P<0.10)$ during the day, compared with the least-efficient animals (Montanholi et al., 2010). The most-efficient steers also had $15 \%$ fewer visits to the feeder overnight (2000-0800 h; Montanholi et al., 2010). In the present study, the efficient heifers had longer individual meals, but a shorter daily feeding duration than the least-efficient animals.

Feeding patterns are important in pastoral grazing where a new allocation of feed is presented after morning and afternoon milking (about 0800 and $1400 \mathrm{~h}$ ), because animals with a drive to eat at these times will benefit from a higher-quality sward and require less effort to harvest compared with pasture already grazed (Gregorini, 2012). However, they need to eat rapidly to utilize available pasture, and further research into grazing patterns and their effects on performance is warranted to ensure that selection for negative RFI does not compromise herd productivity.

\section{CONCLUSIONS}

Feeding behavior was not strongly related to RFI or ADG of dairy heifers. When considering groups with divergence for RFI, the most-efficient animals ate less, spent less time feeding, had fewer meals, ate more slowly, had longer meals, and tended to spread their eating patterns more evenly over the day than the least-efficient animals. However, it was not possible to determine whether differences in feeding behavior contributed to differences in RFI or whether an animal's RFI affected its feeding behavior. Future research should investigate animals with divergent RFI when grazing pasture.

\section{ACKNOWLEDGMENTS}

The authors thank Barbara Dow (DairyNZ, Hamilton, New Zealand) for her statistical expertise and the Westpac Taranaki Agricultural Research Station (Hawera, New Zealand) technical team for daily management of the calves. This project was funded by DairyNZ Inc. (Hamilton, New Zealand), Livestock Improvement Corporation (Hamilton, New Zealand), New Zealand Trade and Enterprise (Wellington, New Zealand), and the Ministry of Business, Innovation and Employment (Wellington, New Zealand; contract number DRCX0702).

\section{REFERENCES}

Bingham, G. M., T. H. Friend, P. A. Lancaster, and G. E. Carstens. 2009. Relationship between feeding behavior and residual feed intake in growing Brangus heifers. J. Anim. Sci. 87:2685-2689.

Dobos, R., and R. Herd. 2008. Spectral analysis of feeding patterns of steers divergent in residual feed intake. Aust. J. Exp. Agric. 48:843-846.

Durunna, O. N., Z. Wang, J. A. Basarab, E. K. Okine, and S. S. Moore. 2011. Phenotypic and genetic relationships among feeding behavior traits, feed intake, and residual feed intake in steers fed grower and finisher diets. J. Anim. Sci. 89:3401-3409. 
Golden, J. W., M. S. Kerley, and W. H. Kolath. 2008. The relationship of feeding behavior to residual feed intake in crossbred Angus steers fed traditional and no-roughage diets. J. Anim. Sci. $86: 180-186$.

Grant, R. J., and J. L. Albright. 2001. Effect of animal grouping on feeding behavior and intake of dairy cattle. J. Dairy. Sci. 84(E. Suppl.):E156-E163.

Gregorini, P. 2012. Diurnal grazing pattern: Its physiological basis and strategic management. Anim. Prod. Sci. 52:416-430.

Herd, R. M., and P. F. Arthur. 2009. Physiological basis for residual feed intake. J. Anim. Sci. 87(E. Suppl.):E64-E71.

Holmes, C. W., and J. R. Roche. 2007. Pastures and supplements in dairy production systems. Pages 221-242 in Pasture and Supplements for Grazing Animals. New Zealand Society of Animal Production Occasional publication No. 14. P. V. Rattray, I. M. Brookes, and A. M. Nichol ed. New Zealand Society of Animal Production, Hamilton, New Zealand.

Huzzey, J. M., T. J. DeVries, P. Valois, and M. A. von Keyserlingk. 2006. Stocking density and feed barrier design affect the feeding and social behavior of dairy cattle. J. Dairy Sci. 89:126-133.

Kelly, A. K., M. McGee, D. H. Crews, A. G. Fahey, A. R. Wylie, and D. A. Kenny. 2010. Effect of divergence in residual feed intake on feeding behavior, blood metabolic variables, and body composition traits in growing beef heifers. J. Anim. Sci. 88:109-123.

Lancaster, P. A., G. E. Carstens, F. R. Ribeiro, L. O. Tedeschi, and D. H. Crews Jr.. 2009. Characterization of feed efficiency traits and relationships with feeding behavior and ultrasound carcass traits in growing bulls. J. Anim. Sci. 87:1528-1539.

Lawrence, P., D. A. Kenny, B. Earley, D. H. Crews Jr., and M. McGee. 2011. Grass silage intake, rumen and blood variables, ultrasonic and body measurements, feeding behavior, and activity in pregnant beef heifers differing in phenotypic residual feed intake. J. Anim. Sci. 89:3248-3261.

Macdonald, K. A., J. W. Penno, A. M. Bryant, and J. R. Roche. 2005. Effect of feeding level pre- and post-puberty and body weight at first calving on growth, milk production, and fertility in grazing dairy cows. J. Dairy Sci. 88:3363-3375.

Montanholi, Y. R., K. C. Swanson, R. Palme, F. S. Schenkel, B. W. McBride, D. Lu, and S. P. Miller. 2010. Assessing feed efficiency in beef steers through feeding behavior, infrared thermography and glucocorticoids. Animal 4:692-701.

Nkrumah, J. D., D. H. Crews Jr., J. A. Basarab, M. A. Price, E. K. Okine, Z. Wang, C. Li, and S. S. Moore. 2007. Genetic and phenotypic relationships of feeding behavior and temperament with performance, feed efficiency, ultrasound, and carcass merit of beef cattle. J. Anim. Sci. 85:2382-2390.

Nkrumah, J. D., E. K. Okine, G. W. Mathison, K. Schmid, C. Li, J. A. Basarab, M. A. Price, Z. Wang, and S. S. Moore. 2006. Relationships of feedlot feed efficiency, performance, and feeding behavior with metabolic rate, methane production, and energy partitioning in beef cattle. J. Anim. Sci. 84:145-153.

Payne, R. W., D. A. Murray, S. A. Harding, D. B. Baird, and D. M. Soutar. 2009. GenStat for Windows, 12th ed. Introduction. VSN International Ltd., Hemel Hempstead, Hertfordshire, UK.

Phillips, C. J. C. 2004. The effects of forage provision and group size on the behavior of calves. J. Dairy Sci. 87:1380-1388.

Richardson, E. C., and R. M. Herd. 2004. Biological basis for variation in residual feed intake in beef cattle. 2. Synthesis of results following divergent selection. Aust. J. Exp. Agric. 44:431-440.

Robinson, D. L., and V. H. Oddy. 2004. Genetic parameters for feed efficiency, fatness, muscle area and feeding behaviour of feedlot finished beef cattle. Livest. Prod. Sci. 90:255-270.

Schwartzkopf-Genswein, K. S., S. Atwood, and T. A. McAllister. 2002. Relationships between bunk attendance, intake and performance of steers and heifers on varying feeding regimes. Appl. Anim. Behav. Sci. 76:179-188

USDA-ERS (US Department of Agriculture-Economic Research Service). 2011. Commodity costs and returns. Accessed Aug. 2, 2012. http://www.ers.usda.gov/data-products/commodity-costsand-returns.aspx.

Waghorn, G. C., and R. S. Hegarty. 2011. Lowering ruminant methane emissions through improved feed conversion efficiency. Anim. Feed Sci. Technol. 166-167:291-301.

Waghorn, G. C., K. A. Macdonald, Y. Williams, S. R. Davis, and R. J. Spelman. 2012. Measuring residual feed intake in dairy heifers fed an alfalfa (Medicago sativa) cube diet. J. Dairy Sci. 95:1462-1471. 